\title{
ENSINO À DISTÂNCIA: ESTRATÉGIAS DE UMA UNIVERSIDADE FEDERAL
}

\section{RESUMO}

Este estudo tem como objetivo analisar, em termos estratégicos, a modalidade de ensino à distância no curso de graduação na Universidade Federal de Lavras, UFLA. A pesquisa é de natureza qualitativa, do tipo descritiva, e tem a UFLA como objeto de estudo. O método utilizado foi o de estudo de caso. A metodologia adotada para a coleta de dados foi apoiada em trabalhos de levantamento de fontes secundárias e no uso de técnicas de entrevistas individuais gravadas com aplicação de questionário semiestruturado para cinco pessoas. A análise dos dados está baseada na abordagem interpretativa. Atualmente o comportamento estratégico se aproxima mais de uma estratégia analítica, , pois ela tem uma postura de observadora e de cautelosa em relação ao ambiente. Na medida em que a universidade perceber que o ambiente externo está mudando e que tem agilidade para se adaptar a essa mudança, aproveitará melhor as oportunidades e sofrerá menos as consequências das ameaças.

Palavras-chave: Ensino a Distância, Universidade Federal, Graduação, Estratégia, Administração.

\section{ABSTRACT}

This stdy it has as objective to analyze, in strategical terms, the education modality in the distance in the graduation course in the Lavras Federal University, UFLA. The present research is considered of qualitativa, of the descriptive type, deing the UFLA object of this study. The chosen method was the case study. The methodology to effect the collection of data was the survey in secondary sources and recorded individual interviews with application of questionnaire half-structuralized for five people. The analysis of the data if it bases in the interpretation boarding. Currentyly the strategical behavior if approaches more than analytical strategy, therefore the position of the uniiversity is of observing of the envirolment and cautious. In the measure that the university to perceive that the external envirolment is moving and it has agility to adapt itself to this change, it will use to advantage the chances better and it will suffer the consequences.

Key-words: Education in the Distance, Strategies, Federal University, Administration, Graduation.
Viviane Santos Pereira

Doutorado em Administração pela

UFLA

Professora da Universidade Federal de Lavras/UFLA vivivanesantospereira@yahoo.com.

Luiz Marcelo Antonialli

Doutorando em Administração pela USP

Mestre em Administração Rural pela USP lmarcelo@ufla.br
Recebido em 23/março/2011 Aprovado em 27/junho/2011 


\section{INTRODUÇÃO}

Atualmente, percebe-se a crescente necessidade de aquisição de conhecimento por parte da sociedade. No contexto social, político e econômico vivido - em que as exigências para a inserção no mercado de trabalho ou mesmo a permanência nele estão cada vez mais ligadas à educação - torna-se necessária a formação de profissionais de nível superior. Dessa forma, novas modalidades de ensino, como o método à distância, têm papel importante para suprir essa carência. É sabido que o uso de técnicas de "Educação à Distância" não é uma novidade no mundo, entretanto o debate sobre o papel da educação em uma sociedade de caráter acentuadamente multicultural é recente, tanto nacional como internacionalmente.

O Ministério da Educação tem se empenhado nesse sentido, com o Projeto Universidade Aberta do Brasil, objetivando aumentar a oferta e a qualidade de ensino superior gratuito no país. Diversas universidades federais e estaduais estão envolvidas nesse projeto, com o compromisso de transformar este projeto-piloto em cursos de graduação contínuos. São oferecidos cursos de graduação à distância em várias áreas do conhecimento, com destaque para a área de Administração. A educação a distância tem sido uma modalidade cada vez mais presente na sociedade devido às condições em que ele ocorre, ou seja, pessoas que por um motivo ou outro têm dificuldades de ingressar no ensino de graduação presencial.

Submetidas a uma grande pressão pela modernização e adequação às exigências culturais, sociais, políticas, científicas e econômicas, as Instituições de Ensino Superior precisam, independentemente da modalidade de ensino, segundo Porto (2004, p.2), “[...] entrar em sintonia permanente com o ambiente externo (o desafio da efetividade com legitimação social); qualidade, alcance e inovação no portifólio de produtos e serviços (o desafio da eficácia organizacional); e o melhor uso possível dos seus recursos (o desafio da eficiência)".

Qualquer organização que pretenda manter-se, expandir-se e alcançar sucesso no mercado atual terá de se preocupar com a elaboração de estratégias para ter condições de competir. É preciso conhecer profundamente o mercado em que está inserida, bem como suas próprias forças e fraquezas. Nesse sentido, é de se esperar que a as universidades pensem nessa modalidade de ensino de maneira estratégica. As universidades possuem metas a cumprir, necessitam utilizar uma variedade de recursos, formular estratégias e desenvolver sistemas de planejamento para alcançar os resultados desejados, o que exige um aperfeiçoamento constante em seus processos de gestão.

Kast e Rosenzweig (1987) salientam que a universidade "[...] é uma instituição única na sociedade [...[", e que "[...[ os sistemas tecnológico, estrutural, psicossocial e administrativo da universidade são expressamente diversos das outras organizações. É fundamental observar as características peculiares das organizações universitárias, bem como em suas modalidades de ensino para se discutir a aplicação de estratégias no cenário acadêmico.

A discussão sobre a metodologia de ensino à distância nas universidades públicas é recente, sendo pertinente o aprofundamento sobre o tema. A partir do exposto questiona-se: a modalidade de ensino à distância para cursos de graduação tem sido pensada estrategicamente pelas universidades? Qual a postura estratégica das universidades em relação a essa modalidade?

\section{OBJETIVOS}

\subsection{Objetivo Geral}

Este estudo tem como objetivo analisar, em termos estratégicos, a modalidade de ensino a distância no curso de graduação na Universidade Federal de Lavras.

\subsection{Objetivos Específicos}

- Descrever como se deu o surgimento e a implantação dessa modalidade na universidade.

- Analisar o ambiente, identificando os pontos fortes e fracos, bem como as oportunidades e ameaças em relação ao curso de graduação modalidade à distância.

- Identificar o comportamento estratégico da universidade em relação a essa modalidade de ensino, segundo a tipologia de Miles e Snow.

\section{ENSINO À DISTÂNCIA}


Entre as várias formas de se definir o conceito de Ensino à Distância (EAD), nota-se um elemento comum: os agentes educacionais, separados espacialmente, se relacionam pela mediação de aparatos técnico-eletrônicos, tais como aqueles que foram citados na composição da infraestrutura do programa Universidade Aberta do Brasil (UAB).

A educação à distancia, na sua essência, é um sistema tecnológico de comunicação bidirecional (ARETIO, 2007). Trata-se, grosso modo, de um processo de ensino disponibilizado para um grande número de pessoas. Segundo o Decreto n. ${ }^{\circ}$ 2494, do ano de 1998, é uma modalidade de ensino que possibilita a autoaprendizagem, com a mediação de recursos didáticos sistematicamente organizados, apresentados em diferentes suportes de informação, utilizados isoladamente ou combinados, e veiculados pelos diversos meios de comunicação (MEC, 2007). Essa nova técnica de ensino não é nova, pelo contrário, já existe há muitos anos. Seu principal diferencial em termos de inovação relaciona-se com as ferramentas tecnológicas utilizadas que facilitam o seu acesso.

Para Gomes et al. (2000), a educação a distância torna-se uma alternativa viável no atendimento, não somente das demandas de grupos específicos em contextos com alta renda e acesso tecnológico, mas também de grupos dispersos geograficamente, com restrições de acesso às tecnologias de $3^{\mathrm{a}}$ geração e com urgente necessidade de atualização e formação, gerada pela obsolescência acelerada dos conhecimentos, causada, por sua vez, pelo avanço tecnológico e científico. A diversidade de demandas e as diferentes possibilidades de acesso às mídias de cada público implicam a existência de diversos modelos de cursos e estratégias pedagógicas a serem consideradas.

Diante dessa visão de aumento de demanda, a administração das organizações de ensino superior precisa ficar atenta às mudanças desse cenário e encontrar várias formas de atingir a eficiência - por meio de mecanismos que propiciem melhores resultados - e ao mesmo tempo manter a qualidade do ensino superior.

Segundo Moran (2007), nos cursos de graduação modalidade à distância a organização pedagógica tem de ser muito mais cuidadosa, pois é difícil manter a motivação no ambiente virtual. $\mathrm{O}$ autor defende o envolvimento dos alunos em processos participativos, afetivos e que inspirem confiança. Nessa perspectiva, o processo de organização do ensino-aprendizagem online é mais complexo e exige uma logística nova, que está sendo testada com mídias telemáticas pela primeira vez, trazendo, portanto, questões pedagógicas específicas com desafios novos para o processo educacional à distância. Ressalta-se que não se pode padronizar e impor um modelo único de educação on-line. É importante experimentar, avaliar e avançar até se ter segurança do ponto de equilíbrio na gestão do virtual, e de caminhar para ampliar as propostas pedagógicas mais adequadas para cada situação de ensino-aprendizagem on-line.

\subsection{Universidade Aberta do Brasil e o Projeto Piloto}

O Projeto Universidade Aberta do Brasil (UAB) foi criado pelo Ministério da Educação, em 2005, no âmbito do Fórum das Estatais pela Educação com o principal objetivo de articular e integrar o sistema nacional de educação superior a distância, em caráter experimental, visando sistematizar as ações, programas, projetos, e as atividades pertencentes às políticas públicas voltadas para a ampliação e interiorização da oferta do ensino superior gratuito e de qualidade no Brasil (UAB, 2006). Quando a discussão envereda para as formas de aplicação dos recursos para a difusão do ensino superior público e de qualidade no nosso país, o programa Universidade Aberta do Brasil surge, de acordo com a Secretaria de Educação a Distância do MEC, como uma alternativa primordial para viabilizar a formação universitária de $30 \%$ dos estudantes brasileiros até 2011. Tratase de uma parceria entre consórcios públicos nos três níveis governamentais (federal, estadual e municipal), a participação das universidades públicas e demais organizações interessadas.

A premência de ações voltadas para a aplicação de recursos que incitem o incremento do ensino universitário situa-se fora de questão, sobretudo quando se considera o fato de que apenas $10 \%$ dos brasileiros de 18 a 24 anos têm acesso aos cursos de graduação nas universidades brasileiras. No bojo de tais ações, destaca-se a criação de um curso-piloto de Administração a distância, engendrado por meio de parecerias estabelecidas entre a Secretaria de Educação a Distância do MEC, o Banco do Brasil e várias 
instituições federais e estaduais de ensino superior. Zuin (2006, p. 9), ao analisar o projeto da Universidade Aberta do Brasil afirma que o estudante será acompanhado por um processo de tutoria que permitirá o monitoramento direto do desempenho e do fluxo de atividades, facilitando a interatividade e identificação de possíveis dificuldades de aprendizagem.

Como se observa, consiste num projeto de grande envergadura e que se torna, de acordo com as pretensões governamentais, decisivo para o alcance da meta de propiciar a $30 \%$ dos estudantes brasileiros o acesso à formação superior até o ano de 2011. É notória a importância do aumento do índice de estudantes universitários em um país, sobretudo quando se considera o real significado do processo educacional/formativo universitário e seus desdobramentos na produção do conhecimento tecnológico. Em meio à miríade de políticas educacionais patrocinadas pelo governo brasileiro, as quais se coadunam no objetivo de que seja arrefecida nossa defasagem universitária em relação a outros países, o programa UAB se diferencia não só pelos consórcios estabelecidos entre os três níveis governamentais, mas principalmente por se caracterizar um programa de formação universitária na modalidade de educação à distância (EaD).

A demanda social por uma formação superior à distância é crescente. De acordo com relatório da Comissão Assessora para a Educação Superior à Distância do MEC “[...] o cenário educacional contemporâneo mostra uma forte tendência: a crescente inserção dos métodos, técnicas e tecnologias de educação à distância em um sistema integrado de oferta de ensino superior, permitindo o estabelecimento de cursos com combinação variável de recursos ensino-aprendizagem, presenciais e não presenciais, sem que se criem dois sistemas de formação separados e mutuamente excludentes". $\mathrm{O}$ relatório destaca o potencial que tais tecnologias possuem para estimular o acesso de um número maior de estudantes no nível superior (MEC, 2006, p. 4). Quanto ao tipo de curso a ser oferecido e a possibilidade de realizá-lo mediante uso dessa tecnologia, o mesmo relatório ainda pondera que " [...] a atribuição de maior ou menor presença, maior ou menor uso de tecnologia nos processos educativos de nível superior será determinada pela ponderação da natureza do curso, de seus objetivos e conteúdos, e da possibilidade de acesso metodológico à tecnologia adequada" (MEC, op. cit.).

Para a consecução do Projeto UAB, o Ministério de Educação, por meio da Secretaria de Educação à Distância (SEED), lançou o Edital $\mathrm{N}^{\circ} 1$, em 20 de dezembro de 2005, com a Chamada Pública para a seleção de polos municipais de apoio presencial e de cursos superiores de Instituições Federais de Ensino Superior na Modalidade de Educação à Distância para a UAB.

Em relação especificamente ao curso-piloto de graduação em Administração à Distância do UAB tratase de uma parceria entre o MEC-SEED, o Banco do Brasil (integrante do Fórum das Estatais pela Educação) e Instituições Federais e Estaduais de Ensino Superior.

Em cada unidade da federação, as universidades definirão os locais dos polos regionais e sua infraestrutura para atendimento aos estudantes para os momentos presenciais. O estudante será acompanhado por um processo de tutoria que permitirá o monitoramento direto do desempenho e do fluxo de atividades, facilitando a interatividade e a identificação de possíveis dificuldades de aprendizagem.

\section{ESTRATÉGIA}

Para Hofer \& Schandel (1978), estratégia é o estabelecimento dos meios fundamentais para atingir os objetivos, sujeito a um conjunto de restrições do meio envolvente. Supõe a descrição dos padrões mais importantes de utilização de recursos e a descrição das interações mais relevantes com o meio envolvente.

Kaplan e Norton (2002, p. 82) enfatizam que qualquer estratégia deve ter como essência proporcionar valor para o cliente, descrevendo uma combinação de atributos de produtos e serviços, de relacionamento com os clientes e de imagem corporativa. Tal estratégia tem de definir o diferencial da empresa entre seus concorrentes, com a finalidade de atrair, reter e aprofundar relacionamentos com os clientes. "A proposição de valor é crucial, porque ajuda a organização a conectar seus processos internos à melhoria dos resultados com os clientes."

Estratégia é hoje uma das palavras mais utilizadas na vida das organizações e encontra-se abundantemente presente quer na literatura da especialidade, quer nos textos mais comuns, mesmo de âmbito jornalístico. 
À primeira vista, parece ter relação com um conceito estabilizado, de sentido consensual e único, de tal modo que, na maior parte das vezes, entende-se ser escusada a sua definição. Contudo, um pouco de atenção ao sentido em que a palavra é usada permite, desde logo, perceber que não existe qualquer uniformidade, podendo o mesmo termo referir-se a situações muito diversas.

$\mathrm{O}$ conceito de estratégia vem sendo utilizado de maneira indiscriminada na área da Administração, podendo significar desde um curso de ação formulado de maneira precisa, todo o posicionamento em seu ambiente, até toda a alma, a personalidade e a razão existencial de uma organização. Consiste numa conceituação de grande emprego acadêmico e empresarial, dotada de uma grande amplitude e diversificação, que em alguns aspectos é complementar e em outros divergente (MEIRELLES e GONÇALVES, 2001).

Mesmo com essa discussão teórica, não se pode negar que o crescimento do porte das organizações e o incremento da sua complexidade estrutural, associados à aceleração do ritmo das mudanças ambientais, têm exigido das organizações uma maior capacidade de formular e implementar estratégias que possibilitem superar os crescentes desafios e atingir os seus objetivos. A velocidade de ocorrência das mudanças no ambiente de mercado pode estar associada a vários fatores, com destaque para o desenvolvimento tecnológico, a integração de mercados, o deslocamento da concorrência para o âmbito internacional, a redefinição do papel das organizações, além das mudanças no perfil demográfico e nos hábitos dos consumidores (MEIRELLES, 1995).

A formulação e a implementação de estratégias, impõem vários desafios à organização: escolher entre reduzir de maneira defensiva, manter ou aumentar, escolha que envolve um grande esforço por parte da organização como um todo. A seleção do melhor método leva em conta o tempo gasto para a implementação, o custo e o controle do processo escolhido.

Para muitas organizações, o dinâmico processo de ajuste às mudanças e às incertezas ambientais é muito complexo, envolvendo grande quantidade de decisões e comportamentos. A adaptação ao ambiente é necessária a fim de que a organização consiga ser sustentável, mantendo um efetivo alinhamento com seu ambiente, ao mesmo tempo em que gerencia eficientemente as interdependências internas (Miles e Snow, 1978). No processo de adaptação organizacional, a organização necessita fazer escolhas estratégicas, optando por percorrer caminhos já conhecidos, ou mesmo procurando alternativas ainda não experimentadas. Por isso, analisar o comportamento estratégico das organizações, bem como seu ambiente externo e interno, é fundamental para orientar o direcionamento da associação.

Todas as organizações, inclusive as instituições de ensino, são afetadas por tendências e sistemas políticolegais, econômicos, tecnológicos, sociais, entre outros. Juntos, esses elementos formam o macroambiente das associações. Como essas forças são muito dinâmicas, suas constantes mudanças criam milhares de oportunidades e ameaças ou restrições para os administradores estratégicos. Cada organização também opera dentro de um ambiente mais específico, denominado microambiente. A estrutura de uma organização influencia a intensidade da competição e cooperação entre as associações que dela fazem parte, impondo algumas restrições em suas operações e oferecendo várias oportunidades para que as organizações bem administradas obtenham diferenciais (WRIGHT, KROLL \& PARNELL, 2000).

\subsection{Comportamento estratégico segundo a tipologia de Miles e Snow}

Por trás das ações empreendidas pelas organizações em busca da sua sustentabilidade e sobrevivência, há todo um comportamento estratégico que as direciona. Comportamento estratégico pode ser entendido como " [...] o processo de interação com o ambiente acompanhado de um processo de promover a modificação das configurações e dos aspectos dinâmicos internos" (Ansoff, 1983, p. 16). O comportamento estratégico compreende todo o processo de adaptação organizacional à turbulência ambiental, considerando a dinâmica intraorganizacional.

Ao apresentarem sua tipologia de comportamento estratégico, Miles e Snow (1987) advertem que nenhuma tipologia é apropriada para demonstrar todas as formas de comportamento organizacional, uma vez que as organizações são muito diversas, mutáveis e complexas. Entretanto, acreditam os autores que não é possível compreender totalmente o comportamento organizacional como um sistema, se não existem conceitos apropriados para esse nível de análise. 
Afirmam os autores que sua tipologia organizacional permite a compreensão do comportamento estratégico de cada organização, com características deum tipo específico, predominantemente. Assim, as organizações não são puramente defensoras, por exemplo. O comportamento puro é apenas existente em termos conceituais. A prática, naturalmente, é bem mais complexa, fazendo com que a classificação seja realizada em termos de predominância de padrões de comportamento.

A tipologia estratégica de Miles e Snow reduz a maioria dos padrões de comportamentos organizacionais a quatro tipos básicos: explorador, defensor, analista e reativo. Cada um desses tipos organizacionais tem sua própria estratégia adaptativa para enfrentar as mudanças do ambiente, podendo, até mesmo, agir para criá-lo. Servem à descrição e ao diagnóstico de padrões de comportamentos organizacionais existentes e à prescrição de alternativas de direcionamentos para mudanças estratégicas que se façam necessárias (MILES e SNOW, 1978, p. 5). As características gerais das formas organizacionais observadas são as seguintes:

- Estratégia defensiva - a empresa procura localizar e manter uma linha de produtos/serviços relativamente estável com enfoque mais limitado que seus concorrentes, tentando proteger seu domínio por melhor qualidade, por serviços superiores e/ou menores preços. Não procura estar entre os líderes, restringindo-se ao que sabe fazer tão bem ou melhor que qualquer um;

- Estratégia prospectiva - a empresa está continuamente ampliando sua linha de produtos e serviços. Enfatiza a importância de oferecer novos produtos e serviços em uma área de mercado mais ampla. Valoriza ser uma das primeiras a oferecer novos produtos, mesmo que todos os esforços não se mostrem altamente lucrativos;

- Estratégia analítica - a organização procura manter uma linha limitada de produtos/serviços relativamente estável e ao mesmo tempo adicionar um ou mais novos produtos/serviços que foram bem-sucedidos em outras empresas do setor. É uma posição intermediária entre as estratégias defensivas e prospectiva;

- Estratégia reativa - a empresa adota um comportamento mais inconsistente do que os outros tipos. É uma espécie de não estratégia. Não arrisca em novos produtos/serviços a não ser quando ameaçada por competidores. A abordagem típica é esperar para ver e responder somente quando forçada por pressões competitivas para evitar a perda de clientes importantes e/ou manter a lucratividade.

Miles e Snow (1978) afirmam que as escolhas organizacionais, no que se refere a comportamento estratégico, são limitadas pelas crenças dos administradores a respeito da direção e do controle dos recursos humanos, configurando-se, assim, aspectos definidores da habilidade da organização em se adaptar ao ambiente. Gimenez (1998) assinala que entre as diversas taxonomias existentes para estratégia, a proposta por Miles e Snow tem tido ampla aceitação pelos pesquisadores na área de administração estratégica.

Snow e Hrebiniak (1980) propõem um modo de identificar o tipo de comportamento estratégico preponderantemente adotado em uma organização. Sua proposta é chamada de "enfoque do parágrafo" e consiste na apresentação ao dirigente de quatro parágrafos que descrevem, sumariamente, os quatro tipos de comportamento estratégico. $\mathrm{O}$ dirigente deve escolher aquele que melhor descreve sua organização. $\mathrm{O}$ questionário enviado à população desta pesquisa também apresentou uma questão com o enfoque do parágrafo, adaptada de Snow e Hrebiniak (1980).

\subsection{Análise ambiental}

As transformações do mundo globalizado e a velocidade das inovações nos tempos atuais têm marcado a sociedade contemporânea por inúmeras descontinuidades e incertezas que desencadeiam alto nível de competitividade no âmbito empresarial. Sobreviver em mercados competitivos, requer dos administradores estratégicos a capacidade de antecipar estados futuros do ambiente em que a empresa atua ou pretende atuar e, ao mesmo tempo, a sensibilidade para avaliar o comportamento de múltiplas variáveis que compõem a realidade interna e externa da própria organização, requerendo uma avaliação dos aspectos relevantes do ambiente externo, os quais indicam tendências de ocorrência de eventos futuros que poderão representar novas oportunidades ou ameaças para a organização. Observar o ambiente - identificando oportunidades e ameaças, pontos fortes e fracos, os clientes, fornecedores, 
concorrentes e produtos - e o comportamento estratégico possibilitará às organizações conhecerem as forças que as cercam, para poder, após análise detalhada dessas forças, escolher efetivamente a sua estratégia competitiva.

O sucesso da administração depende da criação de um elo entre a organização e seu ambiente. Segundo Oliveira (1997), a análise ambiental tem por base as seguintes premissas: i) a empresa deve considerar o ambiente e suas variáveis relevantes em que está inserida, de modo a detectar as oportunidades a usufruir e as ameaças a evitar; ii) a organização deve ter pleno conhecimento dos seus pontos fortes e fracos no enfrentamento dessa situação; iii) a empresa deve proceder à análise interna e externa de forma integrada, contínua e sistemática.

A análise SWOT é uma poderosa ferramenta de planejamento estratégico, cuja sigla - SWOT - originase das iniciais das palavras inglesas Strenghts (forças), Weaknesses (fraquezas), Opportunities (oportunidades) e Threats (ameaças), justamente os quantro pontos a serem analisados. A identificação e a análise dos pontos fortes, fracos, oportunidades e ameaças fornecem a base para a tomada de decisão estratégica.

- Oportunidades: situações externas, atuais ou futuras, que, se aproveitadas adequadamente, podem influenciar a organização positivamente.

- Ameaças: situações externas, atuais ou futuras, que, se não eliminadas, minimizadas ou evitadas, podem influenciar a organização negativamente.

- Pontos Fortes: características da organização, tangíveis ou não, que podem ser potencializadas para melhorar seu desempenho.

- Pontos Fracos: características da empresa, tangíveis ou não, que devem ser minimizadas para evitar influência negativa no seu desempenho.

As forças e fraquezas são determinadas pela posição atual da organização e se relacionam, quase sempre, a fatores internos. Já as oportunidades e ameaças são antecipações do futuro e estão relacionadas a fatores externos.

O ambiente interno pode ser controlado pelos dirigentes da empresa, uma vez que ele é resultado das estratégias de atuação definidas pelos próprios membros da organização. Dessa forma, durante a análise, no momento da percepção de um ponto forte, a organização deve ressaltá-lo ao máximo; na percepção de um ponto fraco, a empresa deve agir para controlá-lo ou, pelo menos, minimizar seu efeito.

O ambiente externo, por sua vez, está totalmente fora do controle da organização. Mas embora não possa controlá-lo, ela deve conhecê-lo e monitorá-lo com frequência, de forma a aproveitar as oportunidades e evitar as ameaças. Evitar ameaças nem sempre é possível, no entanto pode-se fazer um planejamento para enfrentálas, minimizando suas consequências. A Matriz SWOT deve ser utilizada entre o diagnóstico e a formulação estratégica propriamente dita.

O primeiro passo para o uso da técnica é estabelecer um instrumento de coleta de dados a ser aplicado no ambiente interno da organização. Um questionário ou técnicas de prospecção, tais como Delfos ou Brainstorming podem ser usados para montar uma lista de forças e fraquezas, identificadas entre os gestores posicionados estrategicamente na organização. De posse dessa lista, passa-se a justificar, com argumentos claros e convincentes, cada uma das forças e fraquezas identificadas, além de selecionar as mais significativas, evitando repetições e incongruências, e consolidando, assim, a análise do ambiente interno.

O segundo passo para o uso da SWOT é a coleta de dados do ambiente externo da organização. Aqui, também, a seleção do instrumento a ser usado é de grande importância para a qualidade dos dados a serem coletados. Nessa etapa, o objetivo deve ser a formação de uma lista de oportunidades e ameaças devidamente justificadas com argumentos claros e convincentes. A lista deve passar por um julgamento criterioso, em que repetições e possíveis incongruências serão eliminadas, na conclusão do trabalho de análise do ambiente externo.

O terceiro passo é dispor, por ordem de prioridade, as forças, fraquezas, oportunidades e as ameaças mais influentes no cumprimento da missão e dos objetivos da organização em uma matriz. Esse procedimento tem por função obter um panorama geral do resultado da sondagem ambiental e permitir o julgamento correto dos gestores quanto aos acontecimentos da situação atual da organização.

O quarto e último passo consiste no julgamento 
dos gestores dos itens ambientais coligidos na matriz SWOT. Esse julgamento vai ensejar a elaboração de um relatório de diagnóstico situacional que deverá embasar as decisões estratégicas a serem tomadas a seguir. Essa etapa consolida todo o trabalho realizado com base na técnica, para "fotografar" a situação atual da organização, fornecendo o conhecimento das forças, fraquezas, oportunidades e das ameaças que irão subsidiar as decisões quanto à avaliação e à escolha da estratégia para a elaboração e a implementação do planejamento estratégico.

A Análise SWOT é uma ferramenta utilizada para fazer análise de cenário (ou análise de ambiente), sendo usada como base para a gestão e o planejamento estratégico de uma corporação ou empresa, mas podendo, por causa de sua simplicidade, ser empregada em qualquer tipo de análise de cenário. Ela é um sistema simples para posicionar ou verificar a posição estratégica da empresa no ambiente em questão. Essa análise de cenário se divide em ambiente interno (forças e fraquezas) e ambiente externo (oportunidades e ameaças).

Na técnica SWOT, o objetivo é, segundo Silveira (2001), fornecer informações necessárias e permitir uma avaliação consistente do ambiente interno e dos impactos do ambiente externo, coerente com os recursos disponíveis. Silveira (2001) acrescenta que compreender e utilizar o conhecimento gerado com base numa análise ambiental - como a proposta SWOT -- pode tornar claras as áreas em que as mudanças estratégicas são passíveis de gerar os melhores resultados.

Em virtude de sua simplicidade de aplicação, tanto para empresas, como para produtos e serviços, o modelo SWOT é amplamente utilizado, apesar de apresentar algumas limitações, devido à subjetividade de julgamento e também à dificuldade em discernir quais os fatores internos e externos. Entretanto, por ser representado geralmente em forma de matriz, permite que seja demonstrada a situação atual do negócio de maneira simples e de fácil entendimento.

\section{METODOLOGIA}

A presente pesquisa é considerada de natureza qualitativa. Quanto à natureza das variáveis estudadas, Kirk \& Miller (1986) comentam que na pesquisa qualitativa os dados são colhidos por meio de perguntas abertas, em entrevistas em grupos, em entrevistas individuais em profundidade e em testes projetivos.

Para se realizar uma pesquisa na área de ciências sociais existem diversas formas e todas possuem seu valor, não se podendo assegurar que uma é melhor do que outra. O que se pode afirmar é que uma técnica está mais adequada ao tipo de pesquisa a ser realizada (Yin, 1994).

Para esta pesquisa optou-se pela pesquisa do tipo descritiva. De acordo com Mattar (1993), as pesquisas descritivas se constituem de objetivos bem definidos e procedimentos formais, além de serem bem estruturadas e dirigidas para a solução de problemas ou para a avaliação de alternativas de cursos de ação. Segundo o autor, a pesquisa descritiva visa fornecer ao pesquisador dados sobre as características de grupos, estimar propor $\neg$ ções de determinadas características e verificar a existência de relações entre variáveis.

O objeto deste estudo consiste no curso de graduação modalidade à distância da Universidade Federal de Lavras (UFLA). Para possibilitar a descrição da modalidade enfocada, examinando-a em profundidade, utilizou-se o método de estudo de caso (Bogdan \& Bicklen, 1994; Babbie, 1999; Laville \& Dionne, 1999).

A estratégia estudo de caso, segundo Babbie (1999), permite coletar e examinar o máximo possível de dados sobre um determinado tema, procurando a descrição a mais abrangente do grupo e tentando determinar as interrelações lógicas dos seus vários componentes. Dessa forma, o estudo de caso incide sempre sobre um caso em particular, examinado detalhadamente, conforme apontam Laville e Dionne (1999).

Quanto à metodologia para efetuar a coleta de dados optou-se por aplicar a proposta de Mattar (1993):

a) Levantamentos em fontes secundárias de dados: levantamentos bibliográficos em livros, revistas, trabalhos acadêmicos, informações jornalísticas, informações de órgãos governamentais e outras;

b) Entrevistas individuais gravadas com aplicação de questionário semiestruturado: nessa etapa, o objetivo foi o de aprofundar o conhecimento sobre o assunto com o fim de explicar os fatos e fenômenos observados.

Foram entrevistadas 5 pessoas consideradas importantes no processo de implantação e no 
desenvolvimento atual do curso, os quais ocupam ou ocupavam os seguintes cargos: coordenador do curso de administração modalidade à distância à época; coordenador atual do curso; pró-reitor de graduação na época, que é o atual; coordenadora do centro de educação à distancia; chefe do departamento de administração e economia na época.

Para a análise dos dados, o estudo está baseado na abordagem interpretativa. Para a abordagem interpretativa ou teoria social, de acordo com Alencar \& Gomes (1998), a essência da vida social está baseada na habilidade que os seres humanos possuem de examinar o que acontece a sua volta e, com base nisso, escolher como agir à luz dessa interpretação. Embora ela tente explicar os motivos pelos quais as pessoas se comportam de uma determinada maneira, tal explicação não repousa exclusivamente na influência de fatores externos aos indivíduos ("estrutura de valores e normas" e "desigualdade estrutural").

Os teóricos da ação acentuam a necessidade de concentrar no nível micro de análise da vida social (nos modos pelos quais indivíduos são capazes de interagir uns com os outros), ao contrário de se concentrar no nível macro (nos modos pelos quais a estrutura da sociedade influencia o comportamento dos indivíduos). Consideram que não se deve pensar a existência da sociedade como algo fora e antes da interação entre indivíduos. Para os teóricos da ação, sociedade é o resultado final da interação humana, não sua causa. Somente observando como os seres humanos são capazes de interagir, o pesquisador poderá entender como a ordem social é criada.

Esse modo de conceber a realidade enfatiza a necessidade de compreender o significado que as pessoas atribuem aos objetos de orientação que formam a situação na qual atuam. Segundo Taylor (1979), quando se fala de significado está se usando um conceito que possui a seguinte articulação: significado existe para um indivíduo e é de alguma coisa (objeto de orientação) que se encontra em um contexto.

Para Alencar \& Gomes (1998), essa articulação quer dizer que não existe significado no vácuo, mas para um indivíduo específico ou grupo de indivíduos em um dado contexto. Em segundo lugar, admite-se que para indivíduos e contextos diferentes o mesmo objeto poderá ter significados variados. Assim, pode-se distinguir, em um objeto de orientação, diferentes significados e isto não quer dizer que o objeto de orientação e o seu significado sejam fisicamente separáveis, mas que ele tem duas descrições, em uma das quais ele é caracterizado em termos do significado para o indivíduo.

\section{RESULTADOS E DISCUSSÕES}

\subsection{Surgimento do curso de graduação modalidade a distância}

De acordo com o pró-reitor de graduação, o ensino de graduação à distância fazia parte do Plano de Desenvolvimento Institucional (PDI) da Universidade Federal de Lavras (UFLA), porém a universidade ainda não se havia mobilizado para colocá-lo em funcionamento. Segundo o primeiro coordenador do curso de graduação em administração modalidade à distância, foi o prefeito da cidade de Campos Gerais que, atento à política do governo favorável ao ensino de graduação à distância, por meio do projeto $\mathrm{UAB}$, propôs à reitoria realizar parceria, despertando-a para essa oportunidade. Assim, o chefe do Departamento de Administração e Economia (DAE) recebeu visita de um representante do Banco do Brasil do município de Lavras, o qual veio conversar sobre o interesse da instituição no projeto da UAB e na possibilidade de parceria com a universidade.

Posteriormente a essa discussão, o DAE iniciou diálogo com a pró-reitoria de graduação, para conhecer e estudar a possibilidade de implantação do ensino de graduação à distância na universidade, formando uma comissão para estudar essa viabilidade, que participou de reuniões em Brasília com o MEC e BB sobre o projeto UAB.

A pró-reitoria, após se mostrar favorável ao projeto, informa todos os departamentos do projeto e os convida a participar. O Departamento de Administração e Economia é o único que aceita o desafio, até porque, segundo o chefe do departamento, o DAE já tinha ideia de ampliar sua área de atuação, pela inserção da universidade em outras localidades. Mesmo diante da resistência e das incertezas, pela falta de experiência com essa modalidade no ensino de graduação - pois já possui vasta experiência no ensino de pós-graduação a distância -, obteve sucesso na aprovação pelo conselho universitário e pelo Conselho de Ensino, Pesquisa e Extensão (CEPE). A universidade passa a fazer parte do projeto piloto do MEC e cria o projeto político pedagógico para auxiliar nesse processo de implantação.

Vários fatores levaram a universidade a optar por 
essa nova técnica educativa, sendo destacados pelos entrevistados os seguintes: i) a política do governo federal favorável à expansão do ensino público superior pela modalidade à distância; ii) o cumprimento da função social da instituição como agente do desenvolvimento, levando o ensino aos que estão em processo de formação; iii) a ação estratégica da universidade, sobretudo do DAE, para aproveitar a oportunidade de expansão de suas fronteiras; iv) a oportunidade de conhecer e experienciar essa modalidade de ensino em voga e de obter recursos para a instituição.

Essa foi, portanto, uma decisão estratégica da universidade. Diante das circunstâncias, pode-se dizer que foi uma estratégia emergente num primeiro momento e posteriormente deliberada. Ela aproveitou a oportunidade em que as políticas públicas sinalizaram para o ensino à distância, respondendo à pressão do ambiente. Apesar de o processo educacional à distância já fazer parte da política da instituição, foi após esse primeiro momento que a universidade passou a organizar, discutir e planejar suas ações diante dessa modalidade de ensino.

O Departamento de Administração e Economia, como único departamento a fazer parte do projeto, tomou frente no processo de implantação e ficou responsável por estruturá-lo e por criar as condições necessárias para seu funcionamento. Nesse processo, surgiram muitas dúvidas e dificuldades, pois apenas em agosto de 2008 foi criado um órgão específico, o Centro de Ensino à Distancia (CEAD), responsável pelo gerenciamento desse modelo de ensino na instituição e pelo fornecimento de todo o aparato pedagógico indispensável para a sua atividade.

Durante o processo de implantação surgiram muitas dúvidas operacionais, pois não havia know-how com a ambiente virtual de aprendizagem, bem como quais seriam as regras e normas que regulamentassem seu funcionamento. Diante dessas dificuldades o curso teve que ser adiado e sofreu uma defasagem de cerca de 2 meses, iniciando-se em setembro de 2006, comparada com as outras instituições que iniciaram na data prevista. O curso, mesmo necessitando de mais tempo para melhor estruturação teve que ser iniciado, o que gerou bastante trabalho aos profissionais envolvidos para sua consecução.

Outra dificuldade relatada pelos entrevistados nesse processo de implantação do curso foi a resistência da comunidade acadêmica e universitária, já que havia um grande desconhecimento sobre a modalidade, além de muita desconfiança e preconceito.

Após 2 anos e meio, desde a implantação do curso muitas mudanças estruturais ocorreram. Os erros e acertos foram importantes para o aperfeiçoamento do curso. Desde melhorias na contratação de pessoal, tecnologia adequada à infra-estrutura, bem como melhorias nas políticas que regem o curso e maior adesão dos departamentos.

\subsection{Comportamento estratégico}

Os entrevistados ao analisar o comportamento estratégico da UFLA em relação ao curso de graduação modalidade a distância de Minas Gerais declararam ser importante fazer essa análise em dois momentos: no processo de implantação e no momento atual.

No início do curso todos os entrevistados concordaram que a universidade adotava um comportamento estratégico reativo, pois ela não se arrisca em novos cursos a não ser quando ameaçada ou pressionada. Normalmente a abordagem típica é esperar para ver e responder somente quando forçada por pressões competitivas. A universidade teve uma postura cuidadosa no que concerne à entrada de novos cursos nessa modalidade de ensino, mas foi forçada a reagir à demanda do ambiente.

Atualmente o comportamento estratégico da universidade aproxima-se mais de uma estratégia analítica que, de acordo com a tipologia de Miles e Snow, procura manter uma linha mais limitada de cursos relativamente estável e ao mesmo tempo adicionar novos cursos ou serviços que foram bem sucedidos em outras universidades. A postura da universidade é de observadora do ambiente e de cautelosa, buscando adquirir experiência em um curso primeiro para depois pensar em oferecer novos cursos de graduação a distância Segundo um dos entrevistados a universidade não tem intenção de sair na frente das outras universidades federais, mesmo por que a universidade vê as outras universidades como aliadas, com intuito de cooperação, e não de competição. Além disso, na medida em que a universidade percebe que a UAB é uma realidade, passa a ampliar sua matriz de vagas, e a aproveitar, cuidadosamente, essa oportunidade como uma política estratégica de trazer para a instituição, entre outros benefícios, aumento nos recursos. 
Um aspecto que justifica esse comportamento reativo e analítico refere-se a uma característica da universidade de forte atuação em pesquisa e em extensão, o que demanda bastante tempo e envolvimento dos docentes nessas atividades acadêmicas e dificulta a possibilidade de maior ampliação de novos cursos.

\subsection{Análise do ambiente interno e externo: pontos forte e fracos, ameaças e oportunidades}

Após análise do ambiente externo e interno da instituição, chega-se a um quadro que sintetiza a opinião dos entrevistados (Quadro 1). A importância da identificação das forças e das fraquezas é particularmente importante para os aspectos mais diretamente relacionados com os fatores críticos de sucesso da instituição em causa. É também importante referir que a consideração de uma determinada característica da instituição como força ou fraqueza é sempre relativa e potencialmente alterável, designadamente na medida em que se podem verificar ao longo do tempo alterações importantes no seu comportamento.

\section{a) Pontos fortes}

Observa-se que todos os entrevistados declararam que a capacitação dos profissionais, em especial dos professores, e a experiência da UFLA com o ensino à distância na pós-graduação são pontos fortes da instituição.

A UFLA é uma instituição consolidada, com grande experiência nos cursos de graduação, mestrado e doutorado, e conta com um quadro de professores devidamente qualificado. Por isso, os profissionais que se envolveram no curso de graduação na modalidade à distância têm competência técnica para desenvolver as atividades pertinentes. Além disso, a UFLA tem experiência de 21 anos com curso de pós-graduação nessa

QUADRO 1: Análise do ambiente interno e externo do curso de graduação, modalidade a distância, da Universidade

\begin{tabular}{|c|c|c|}
\hline \multicolumn{3}{|c|}{ Federal de Lavras } \\
\hline & Aspectos favoráveis & Aspectos desfavoráveis \\
\hline $\begin{array}{l}\text { A } \mathbf{m} \text { b } \\
\text { interno }\end{array}$ & $\begin{array}{l}\text { Ponto forte: } \\
\text { a) Capacitação dos profissionais (5) } \\
\text { b) Experiência em cursos lato sensu (5) } \\
\text { c) Política da universidade favorável (2) } \\
\text { d) Estrutura mínima da universidade (1) } \\
\text { e) Mobilização do DAE (1) } \\
\text { f) Faz parte do PDI (1) } \\
\text { g) Possui um centro de EAD (1) } \\
\text { h) Marca UFLA (1) }\end{array}$ & $\begin{array}{l}\text { a) Preconceito com a modalidade (5) } \\
\text { b) Deficiência de pessoal técnico administrativo (2) } \\
\text { c) Falta de cursos na área de ciências humanas (1) } \\
\text { d) Universidade relativamente pequena (1) } \\
\text { e) Envolvimento dos docentes em outras atividades (1) } \\
\text { f) Burocracia nas decisões I (1) } \\
\text { g) Pouca experiência com formação de professores (1) } \\
\text { h) falta de experiência o ensino de graduação a distancia } \\
\text { (1) } \\
\text { i) inexistência do AVA (1) } \\
\text { j) imagem da UFLA arranhada devido a demanda } \\
\text { judicial (1) }\end{array}$ \\
\hline $\begin{array}{l}\text { A m b } \\
\text { externo }\end{array}$ & $\begin{array}{l}\text { Oportunidades: } \\
\text { a) Experiência para o ensino presencial (3) } \\
\text { b) Captação de mais recursos para } \\
\text { universidade (3) } \\
\text { c) Formação de profissionais nessa } \\
\text { modalidade (2) } \\
\text { d) Rigor do MEC quanto a qualidade do } \\
\text { ensino nessa modalidade (1) } \\
\text { e) Política do governo favorável (1) } \\
\text { f) Desenvolvimento das tecnologias (1) } \\
\text { g) Difusão da universidade (1) } \\
\text { h) Parcerias (2) } \\
\text { i) Participação em eventos dessa natureza } \\
\text { (1) } \\
\text { j) Cumprimento de sua função social (2) }\end{array}$ & $\begin{array}{l}\text { Ameaças: } \\
\text { a) Crise econômica com política desfavorável (4) } \\
\text { b) falta de credibilidade da sociedade (2) } \\
\text { c) Entrada da rede privada (2) } \\
\text { d) Atraso do curso em relação as outras IFES (1) } \\
\text { e) Evasão no EAD (1) } \\
\text { f) Riscos no relacionamento com os alunos (1) } \\
\text { g) Rigor do MEC quanto a qualidade do ensino (1) } \\
\text { h) relacionamento com os parceiros (1) }\end{array}$ \\
\hline
\end{tabular}

Fonte: Dados da pesquisa

Obs: Entre parênteses estão o número de entrevistados que declararam esses fatores 
modalidade de ensino, não the sendo desconhecidas as atividades relacionadas ao modelo educativo, a exemplo de preparar encontro presencial, de construir material didático, de estabelecer relacionamentos à distância com os alunos.

Dois dos cinco entrevistados (a coordenadora do CEAD e o pró-reitor de graduação) declararam a importância da política da universidade favorável ao ensino à distância, um ponto forte da instituição, pelo apoio dispensado à sua criação e ao seu funcionamento. Outros fatores também foram considerados como pontos fortes, tais como:

- Marca UFLA: a universidade é uma instituição antiga, que possui credibilidade.

- Estrutura mínima: a universidade conta com uma estrutura mínima para dar suporte a essa nova modalidade, como biblioteca, departamento, cantina, salas de aula, anfiteatros, xerox, além de outras instalações de apoio.

- Mobilização do DAE: o departamento e a universidade não pouparam esforço e determinação em implantar essa modalidade de ensino na instituição.

Essas características foram importantes para consolidação do curso e são considerados fatores que devem continuar sendo aproveitadas para manter o bom desempenho que o curso tem alcançado dentro e fora da universidade

\section{b) Pontos fracos}

Dando continuidade à análise do ambiente interno, os entrevistados destacaram como aspectos desfavoráveis o preconceito existente contra a modalidade e a deficiência de pessoal técnico-administrativo. De modo geral, há uma grande desconfiança quanto à qualidade do ensino dessa metodologia virtual. A resistência da comunidade acadêmica (docentes e discentes) esteve e está presente desde o surgimento do curso, pois persiste o receio de a imagem da universidade ser prejudicada ao lançar profissionais no mercado com o mesmo diploma de quem faz um curso presencial. Esse descrédito devese em parte, de acordo com um dos entrevistados, à má qualidade e à falta de seriedade de muitos cursos à distância oferecidos em instituições privadas, que criam uma imagem destorcida e pejorativa desse modelo.

Outros aspectos também foram considerados como pontos fracos, a saber:

- Deficiência de pessoal técnico-administrativo: a falta de recursos humanos para a prática das atividades do curso limita o desenvolvimento de um melhor trabalho.

- Falta de cursos na área de ciências humanas: a universidade em estudo é uma instituição com forte vocação para ciências agrárias, a qual oferece apenas recentemente novos cursos na área de ciências humanas. Se a universidade há muito possuísse tradição de cursos nesta última área talvez já tivesse iniciado outros cursos, além dos de administração, na modalidade à distância, segundo a coordenadora do centro de ensino à distância.

- Envolvimento dos docentes em outras atividades: o pró-reitor dos cursos de graduação alega que a universidade desenvolve intenso trabalho em atividades de pesquisa e extensão, e que isso restringe a adesão dos professores a essa modalidade de ensino, tolhendo-lhes a participação e o engajamento.

- Burocracia nas decisões: a coordenadora do centro de educação à distância afirma que ainda existe muita morosidade no processo de decisões administrativas.

- Pouca experiência com formação de professores: o departamento de educação da UFLA é recente, o que justifica a pouca experiência da universidade com o processo de habilitação de professores.

- Falta de experiência no ensino de graduação à distancia: a universidade, principalmente o departamento de administração, teve de aprender com a prática. $\mathrm{O}$ início do curso com dois meses de atraso em relação às outras IFES teve o lado positivo de aproveitar as experiências boas e más, o que fez com que os erros fossem minimizados.

- Inexistência do AVA: o coordenador do curso à época explicou que o departamento de administração não tinha domínio sobre o Ambiente Virtual de Aprendizagem (AVA), condição que gerou muitas dúvidas sobre como manuseá-lo. Foi necessário valer-se da experiência do Departamento de Ciências Exatas (DEX) para orientar o 
processo.

- Imagem da UFLA prejudicada por causa de demanda judicial: um vestibulando sentiu-se prejudicado no processo seletivo, três meses após o início do curso (dez/2006), e moveu uma ação judicial contra a universidade, que culminou na paralisação do curso. Muitos alunos, por esse problema, desistiram do curso, colocando a universidade, a (UAB), o ensino à distância e o MEC em descrédito.

Todos esses aspectos necessitam ser aperfeiçoados, e a vivência que a universidade está tendo com essa modalidade na base da experiência e do aprendizado adquirido é fator fundamental para a superação das dificuldades enfrentadas.

\section{c) Ameaças}

$\mathrm{Na}$ análise do ambiente externo, quatro entrevistados declararam que a maior ameaça ao curso de graduação na modalidade em questão é a possibilidade de uma política do governo desfavorável ao ensino à distância, motivada por uma crise. Isso porque o projeto UAB tem oferecido muitos incentivos, com a disponibilização de recursos financeiros, os quais dão suporte ao seu funcionamento; a possibilidade de cortes limitaria, pois, a sua funcionalidade.

As estatísticas sobre custos de cursos à distância, com qualidade, mostram que eles são iguais ou mais caros que os cursos presenciais, pois os alunos virtuais necessitam de dedicação individualizada, diferentemente dos alunos presenciais de uma sala de aula, em que o professor atende a todos com base numa única pergunta. Isso demonstra que os medos e as incertezas dos entrevistados são compreensíveis quanto à continuidade de uma política favorável do governo, principalmente com relação à questão econômica.

Outros dois aspectos desfavoráveis considerados como ameaças foram a entrada da rede privada e a falta de credibilidade da sociedade. Ambos os aspectos estão interligados, pois as universidades privadas têm atuado com essa modalidade há um certo tempo e, muitas delas, sem a seriedade de desempenho que lhes seria indispensável, prejudicaram o conceito desse modelo educacional, gerando uma imagem negativa dele perante a sociedade.

Mais outros aspectos qualificados de ameaças foram:

- Rigor do MEC quanto à qualidade do ensino: maior cobrança quanto à eficiência de desempenho do ensino nessa modalidade, minimizando os riscos de cursos que não possam cumprir com esse objetivo.

- Evasão no EAD: alto índice de evasão que ocorre nessa modalidade de ensino, comparada ao modelo presencial.

- Atraso do curso em relação às outras IFES: o atraso ocorrido no início do curso, segundo o coordenador do curso, à época, gerou uma perda de espaço e um descompasso com as outras IFES.

- Riscos no relacionamento com os alunos: cuidado rigoroso por parte de toda a equipe da universidade no processo de comunicação, pois tudo é registrado por escrito, via ambiente virtual de aprendizagem, o que aumenta as possibilidades de problemas.

- Relacionamento com os parceiros: referência às possibilidades de problemas (quebra de acordos) com parcerias estabelecidas com prefeituras, bancos, entre outras instituições.

É importante perceber que as ameaças que venham a afetar o funcionamento da universidade, não são necessariamente más notícias, porque de fato elas podem provocar o aparecimento de uma nova oportunidade na instituição. Para isso, os gestores devem perceber esse novo fato como uma potencialidade; o rigor do MEC quanto à qualidade do ensino, por exemplo, pode ser explorado pela instituição de modo a retirar dele um benefício real, como o reconhecimento de um curso de alta qualidade.

\section{d) Oportunidades}

Para finalizar a análise do ambiente externo, destacam-se a experiência para o ensino presencial e a captação de mais recursos para a universidade como oportunidades de influência positiva para a universidade. Existe uma tendência à incorporação de algumas práticas da modalidade à distancia nos cursos presenciais, de forma 
que a experiência com esse modelo de ensino facilitará este processo.

Além disso, a possibilidade de formação de profissionais nessa modalidade - sendo uma oportunidade de crescimento de pessoal disponível para o EAD - e o cumprimento de sua função social também foram considerados por dois entrevistados como oportunidades da universidade de levar àqueles que por algum motivo não têm condições de ingressar no ensino presencial um ensino de qualidade, ampliando o número de vagas no ensino público.

Ainda, outros fatores foram classificados como oportunidades:

- Rigor do MEC quanto à qualidade do ensino nessa modalidade: aspecto - visto anteriormente como uma ameaça - que se torna uma oportunidade, na medida em que a exigência do MEC na eficiência desse modelo educacional faz com que somente as universidades capacitadas se mantenham ofertadoras de cursos à distância.

- Política do governo favorável: incentivo que o governo tem dado para que a universidade e outras IFES participem do projeto.

- Desenvolvimento das tecnologias: as tecnologias, cada vez mais avançadas e disponíveis, favorecem o desenvolvimento do EAD.

- Difusão da universidade: oportunidade de a universidade ampliar seu campo de atuação e divulgar seu nome e seu trabalho.

- Parcerias: oportunidade oferecida à universidade de realizar parcerias com outras instituições de ensino, com prefeituras e outras organizações.

- Participação em eventos de EAD: oportunidade de aprendizado e troca de experiências da universidade com outras IFES

\section{CONSIDERAÇÕES FINAIS}

Embora seja uma modalidade de ensino reconhecida, que vem ganhando mais espaço, a EAD apresenta novos desafios para os cursos de graduação das Instituições Federais de Ensino Superior (IFES) no contexto educacional, seja nos aspectos pedagógicos, tecnológicos ou de comunicação. O preconceito da comunidade acadêmica contra o ensino à distância é uma importante etapa a ser superada para a inserção da modalidade nas instituições de ensino.

Segundo Tedesco (2004), a maioria dos professores em serviço não tem conhecimento prévio sobre como utilizar as ferramentas do modelo educacional à distância ou sobre quais são suas possibilidades na sala de aula. Ao participarem de um projeto de desenvolvimento profissional alicerçado em uma plataforma virtual os docentes têm de se adaptar a exigências e desenvolver novas habilidades de trabalho, nas quais a informação encontra-se física e virtualmentepresente.

Por isso, as pesquisas em educação e em tecnologias, bem como sua difusão, são fundamentais para que haja compreensão dessa modalidade e para que ela possa ser ampliada, cada vez mais, no processo educacional.

Cabe notar que houve dificuldades no estágio inicial de utilização de ambientes virtuais de aprendizagem (AVA) e demais tecnologias em educação, que geraram medo e incertezas. Mas, com o passar do tempo o curso tem sido aprimorado a partir das experiências vivenciadas e da avaliação processual de cada turma oferecida, num processo constante de construção e reconstrução, promovendo uma excelente oportunidade de aprendizado.

A própria análise do comportamento estratégico da universidade demonstra uma mudança de atitude da instituição: no início do curso, adotou uma postura mais reativa, em que as incertezas estavam mais presentes, e posteriormente assumiu uma postura analítica.

A forma como as estratégias surgem e se implementam obviamente não é um processo idêntico em todas as organizações, resultando antes, de uma conjugação de fatores externos (características e condições do meio envolvente) e de condições internas (dimensão, capacidades materiais e humanas, organizacionais). $\mathrm{Na}$ medida em que a universidade perceber que o ambiente externo está mudando e que tem agilidade para se adaptar a esta mudança, aproveitará melhor as oportunidades e sofrerá menos as consequências das ameaças. Por isso, a análise do ambiente externo é tão importante porque, uma coisa é perceber que o ambiente externo está mudando, outra, é ter competência para adaptar-se a estas mudanças 
(aproveitando as oportunidades e/ou enfrentando as ameaças). Da mesma maneira que ocorre em relação ao ambiente externo, o ambiente interno deve ser monitorado permanentemente.

\section{REFERÊNCIAS}

ALENCAR, E.; GOMES, M.A.O. Metodologia de pesquisa social e diagnóstico participativo. Lavras: UFLA/FAEPE, 1998. $212 \mathrm{p}$.

ANSOFF, H. Igor . Administração Estratégica. São Paulo: Atlas, 1983

ANSOFF, I., 1965, Estratégia Empresarial. McGraw-hill, S. Paulo, 1977,(Trad. ed. 1965).

BABBIE, E. Métodos de pesquisa de survey. Belo Horizonte: Editora UFMG, 1999. 519 p.

BOGDAN, R. C. \& BIKLEN, S. K. Investigação qualitativa em educação. Porto: Porto Ed., 1994. 335 p.

HOFER, C. W. e D. SCHENDEL. Strategy formulation: Analytical concepts. West Publishing Company. 1978

KAPLAN, Robert S.; NORTON, David P. Enfrentando problemas com a estratégia? Mapeie-a. In:

HARVARD BUSINESS REVIEW. Planejamento estratégico. Rio de Janeiro: Elsevier, 2002. (p. 73-94)

KAST, F. E., ROSENZWEIG, J. E. Organização e administração: um enfoque sistêmico. São Paulo: Pioneira, 1987.

GIMENEZ, F. 1998; "Escolhas estratégicas e estilo cognitivo: um estudo com pequenas empresas"; RAC; v.2, n.1; Jan/Abr $27-45$

GOMES, R. C.; RODRIGUES, R. S.; GAMEZ, L.; BARCIA, R. M. Comunicação multidirecional - um ambiente de aprendizagem na educação a distância. In: Congresso Internacional de Educação a Distância. São Paulo, 2000 Disponível em: < www.abed.org.br > Acesso em: 05 abr. 2007.

KIRK, J., MILLER, M. Reliability and validity in qualitative research. Beverly Hills: Sage, 1986. 431p.

LAVILLE, C.; DIONNE, J. A construção do saber. Belo Horizonte: UFMG, 1999. $340 \mathrm{p}$

MATTAR, F.N. Pesquisa de marketing: metodologia, planejamento, execução, análise. São Paulo: Atlas, 1993. v.1, $350 \mathrm{p}$.

MEC - MINISTÉRIO DA EDUCAÇÃO. Relatório da Comissão Assessora para Educação Superior a Distância (Portaria mec $\mathrm{n}^{\circ} .335$, de 6 de fevereiro de 2002) Disponível em: $\quad<$ http://www.portal.mec.gov.br/sesu/arquivos/pdf/EAD. pdf> Acesso em: 16 nov. 2006

MEC - MINISTÉRIO DA EDUCAÇÃO. Decreto n. ${ }^{\mathbf{2}} \mathbf{2 4 9 4}$, de 10 de fevereiro de 1998. Brasília. Disponível em: $<\underline{\text { http:// }}$ portal.mec.gov.br>. Acesso em: 01 abr. 2007.

MEIRELLES, A. M. O planejamento estratégico noBanco Central do Brasil e a viabilidade

estratégica em uma unidade descentralizada da autarquia: um estudo de caso. Dissertação

(Mestrado em Administração) -CEPEA D/FACE/UFMG, Belo Horizonte: UFMG, 1995. 229 p

; GONÇALVES, C. A. O que é estratégia: histórico, conceito e analogias. In: GONÇALVES, C. A.; REIS, M. T.; GONÇALVES, C. (Orgs.). Administração estratégica: multiplos enfoques para o sucesso empresarial. Belo Horizonte: UFMG/CEPEAD, 2001. p. 21-33.

MILES, Raymond e SNOW, Charles C. Organizational strategy, structure, and process. New

York: McGraw-Hill, 1978.

MORAN, J. M. Mudar a forma de ensinar e aprender com tecnologias: transformar as aulas em pesquisa e comunicação presencial-virtual. 1999. Acesso em: 15 abr. 2007 Disponível em: $<$ http://www.eca.usp.br/prof/moran/. . .

OLIVEIRA, D.P.R. Excelência na administração estratégica. São Paulo: Atlas, 1997. 224p.

PORTO, C. Uma introdução ao planejamento estratégico. Disponível em www.senac.br, Acesso em 21 out. 2004.

SILVEIRA, H. In: TARAPANOFF, K., Org. Inteligência organizacional e competitiva.

Brasília : Ed. UnB, 2001. SWOT, p. 209 - 226.

SNOW, Charles C. e HREBINIAK, Lawrence. Strategy, distinctive competence, and organizational

performance. Administrative Science Quaterly, 1980, vol. 25, june, pp. 317-336.

TAYLOR, C. Intepretation and the sciences of man. In: RABINOW, P.; SULLIVAN, W.M. (Org.). Interpretive social science. Berkeley: University of California, 1979. p.25-71.

TEDESCO, Juan Carlos (org). Educação e Novas Tecnologias: esperança ou incerteza?.São Paulo: Cortez; Buenos Aires: Instituto Internacional de Planeaimiento de la Educación; Brasília: UNESCO, 2004.

UNIVERSIDADE ABERTA DO BRASIL. UAB. Acesso em: 18 nov. 2006. Disponível em: <http://www.uab.mec.gov.br/ 
cursopiloto.php >

ZUIN, A. A. S. Educação a distância ou educação distante? O programa universidade aberta do Brasil, o tutor e o professor virtual. Revista Educação e Sociedade, Campinas, vol. 27, n. 96 - Especial, p. 935-954, out. 2006 Disponível em $<\underline{\text { http: } / /}$ www.cedes.unicamp.br >Acesso em: 05 abr. 2007.

YIN, R.K. Case study research: design and methods. 2.ed. California: Sage, 1994. 171p. (Applied Social Reserch Methods Series, 5).

WRIGHT, Peter.; KROLL, Mark J..; PARNELL, John. Administração estratégica: conceitos. 1. ed. São Paulo: Atlas, 2000 . 